\title{
Comunicação
}

[Communication]

\section{Linfoma ósseo em cão}

[Bone lymphoma in a dog]

\author{
N.M. Ocarino, A.E. Silva, R. Serakides, E.G. Melo, S.A. França, T.A. Paixão \\ Escola de Veterinária UFMG \\ Caixa Postal 567 \\ 30123-970 - Belo Horizonte, MG
}

O linfoma é uma neoplasia linfóide maligna que acomete predominantemente os linfonodos, baço e fígado (Meuten, 2002). O linfoma ósseo primário é definido como um tumor intramedular sem evidências de acometimento dos linfonodos (Shoji e Miller, 1971). É considerado raro tanto em seres humanos quanto nos animais domésticos (Turnwald et al., 1987; Thompson e Pool, 2002) e deve ser diferenciado de metástases de linfomas multicêntricos em cães, gatos e bovinos (Langley-Hobbs et al., 1997).

Nos animais, a ocorrência do tumor, aparentemente, não tem predileção pelo sexo, contudo, os homens são mais acometidos que as mulheres (Campbell et al., 2003). Embora existam apenas nove casos de linfoma ósseo primário em cães, seis animais apresentaram idade inferior a um ano o que sugere que a idade de incidência seja menor quando comparado aos casos de linfomas multicêntricos (LanggleyHobbs et al., 1997; Thompson e Pool, 2002).

No homem, os sítios de predileção incluem o fêmur, pélvis, úmero e vértebras (Campbell et al., 2003). Nos cães, as lesões geralmente são múltiplas e salientes, envolvendo tanto os ossos do esqueleto axial quanto apendicular (LanggleyHobbs et al., 1997; Thompson e Pool, 2002).

Recebido para publicação em 23 de abril de 2004

Recebido para publicação, após modificações, em 15 de setembro de 2004

E-mail: serakide@dedalus.lcc.ufmg.br
Radiologicamente, observam-se lesões osteolíticas na metáfise dos ossos longos acometidos, com reação periosteal mínima. Contudo, em alguns ossos onde as lesões se estendem para a diáfise (Rogers et al. 1989), a reação periosteal pode ser difusa e bastante evidente. Assim, o diagnóstico radiológico diferencial inclui mieloma múltiplo, osteomielite e doenças osteometabólicas (Langgley-Hobbs et al., 1997). A confirmação de linfoma ósseo requer a histologia ou citologia das lesões e da medula óssea (Thompson e Pool, 2002).

O objetivo deste trabalho é descrever os achados anatomopatológicos de um caso de linfoma ósseo primário em uma cadela da raça fila de oito anos de idade. O animal foi encaminhado ao hospital veterinário com histórico clínico de paralisia dos membros anteriores que evoluiu rapidamente para decúbito lateral permanente. Ao exame neurológico, os membros anteriores apresentavam sensibilidade e reflexos reduzidos, sensibilidade aumentada no panículo e aumento dos reflexos patelares. Foi realizado hemograma completo e todos os valores se apresentaram dentro da normalidade. Radiologicamente observou-se lise óssea entre a sexta e a sétima vértebras cervicais. Pela suspeita clínica de neoplasia no canal vertebral e pelo prognóstico desfavorável, o animal foi submetido à eutanásia. 
À necropsia, foi evidenciado um nódulo de aproximadamente $4 \mathrm{~cm}$ de diâmetro, brancacento e moderadamente friável na face ventral da sexta e sétima vértebras cervicais que se estendia para o corpo e canal dessas mesmas vértebras (Fig. 1A). Nenhum outro sítio de neoplasia foi evidenciado. As vértebras acometidas foram dissecadas e radiografadas, evidenciando-se extensas áreas de radioluscência com destruição e distorção da sexta vértebra cervical (Fig. 1B). Fragmentos da neoplasia, medula espinhal e vértebras cervicais foram fixados em formalina a $10 \%$ e processados pela técnica rotineira de inclusão em parafina e coloração por hematoxilina-eosina. Os fragmentos ósseos foram previamente descalcificados em solução de ácido fórmico.

À microscopia do corpo da sexta e sétima vértebras cervicais, havia proliferação invasiva e pouco delimitada de células neoplásicas redondas por entre trabéculas ósseas necróticas
(Fig. 1C). Essas células estendiam-se para o canal vertebral e tecidos moles adjacentes. As células neoplásicas, que se apresentavam em padrão sólido ou em cordões sustentadas por fino estroma conjuntivo, apresentavam pleomorfismo intenso, núcleo arredondado, na maioria das vezes com cromatina frouxa, nucléolo evidente e citoplasma escasso. $\mathrm{O}$ índice mitótico era moderado e havia algumas figuras de mitose atípicas (Fig. 1D). Foram observados vasos sangüíneos e linfáticos repletos de células neoplásicas. Havia também áreas de hemorragia e reação periosteal intensa caracterizada por espesssamento do periósteo, hiperplasia osteoblástica e neoformação óssea. Na medula espinhal, havia intensa degeneração axonal, caracterizada por tumefação dos axônios e presença de balões axonais, mas sem infiltração de células neoplásicas. Com base nas características anatomopatológicas foi firmado o diagnóstico de linfoma ósseo primário do tipo linfoblástico.
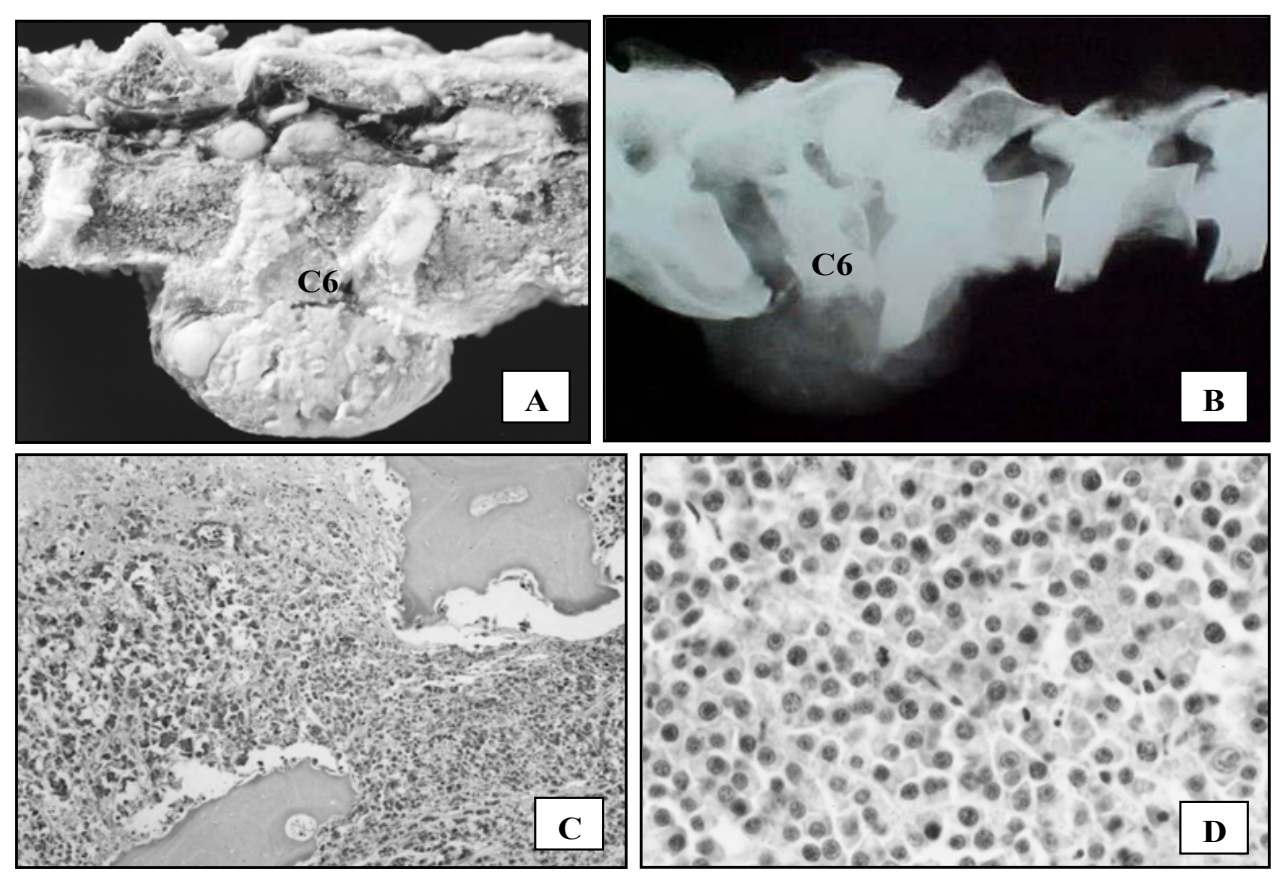

Figura 1. Linfoma ósseo em cão. A- Nódulo de coloração brancacenta na face ventral da sexta (C6) vértebra cervical, estendendo-se para o corpo e canal vertebral. B- Imagem radiológica das vértebras cervicais (C6) com destruição e distorção da sexta vértebra. C- Proliferação de células neoplásicas redondas por entre trabéculas ósseas necróticas. HE, 107×. D- Células neoplásicas pleomórficas, com núcleo redondo com cromatina frouxa, nucléolo evidente, citoplasma escasso e várias figuras de mitose. HE, $643 \times$. 
Os sinais clínicos de paralisia dos membros anteriores, reflexos diminuídos foram decorrentes da compressão medular provocada pela neoplasia. Postula-se que a reabsorção óssea associada com o linfoma resulte de dois mecanismos: o primeiro seria devido a proliferação de células neoplásicas na medula óssea com oclusão vascular, isquemia e necrose seguidas de reabsorção óssea por osteoclasia, o segundo e talvez o mecanismo mais importante, seria devido a produção de fatores humorais pelas células neoplásicas que estimularia a reabsorção óssea local (Barthez et al.,1995).

Palavras-chave: cão, linfoma, osso

\begin{abstract}
It was reported one case of primary bone lymphoma in eight year-old bitch, Fila, with history of anterior limbs paralysis and side lied. A cervical vertebrae neoplasm was suspected and in view of the poor prognosis, the animal was euthanatized. Based on the anatomopathological and histological findings it was firmed the diagnosis of primary bone lymphoma.
\end{abstract}

Keywords: dog, lymphoma, bone

\section{REFERÊNCIAS BIBLIOGRÁFICAS}

CAMPBELL, S.E.; FILZEN, T.W.; BEZZANT, S.M. et al. Primary periosteal lymphoma: an unusual presentation of non-Hodgkin's lymphoma with radiographic, MR imaging, and pathologic correlation. Skeletol Radiol., v.38, p.412-416, 1997.

LANGLEY-HOBBS, S.J.; CARMICHAEL, S.; LAMB, C.R. et al. Polyostotic lymphoma in a young dog: a case report and literature review. $J$. Small Anim. Pract., v.38, p.412-416, 1997.

MEUTEN, D. J. Tumors in domestic animals. 4.ed. Iowa: Iowa State, 2002. 788p.

MOULTON, J.E. Tumors in domestic animals. 3.ed. Berkeley: California, 1990. 672p.
ROGERS, K.S.; JANOVITZ, E.B.; FOOSHEE, S.K. et al. Lymphosracoma with disseminated skeletal involvement in a pup. J. Am. Vet. Med. Assoc., v.9, p.1242-1244, 1989

SHOJI, H.; MILLER, T.R. Primary reticulum cell sarcoma of bone: significance of clinical feature upon the prognosis. Cancer, v.28, p.1234-1244, 1971.

THOMPSON, K.G.; POOL, R.R. Tumors of bones. In: MELTEN, D.J. Tumors in domestic animals. 4.ed. Iowa: Iowa State, 2002. p.245317.

TURNWALD, G.H.; PECHMAN, R.D.; SHIRES, P.K. et al. Lymphosarcoma with osseous involvement in a dog. J. Am. Anim. Hosp. Assoc., v.24, p.350-354, 1987. 